\title{
Elevated Tumor Necrosis Factor (TNF)- $\alpha$ mRNA Expression Correlates with Nuclear Factor Kappa B Expression in Peripheral Blood Mononuclear Cells in Preeclampsia
}

\author{
Zaima Ali1,2, Uzma Zafar1,2, Saba Khaliq ${ }^{1}$ and Khalid Pervaiz Lone ${ }^{1}$ \\ ${ }^{1}$ Department of Physiology and Cell Biology, University of Health Sciences, Lahore, Pakistan \\ ${ }^{2}$ Department of Physiology, Lahore Medical and Dental College, Lahore, Pakistan
}

\begin{abstract}
Objective: To evaluate, compare and correlate the mRNA expression of nuclear factor kappa B (NF-kB) and tumor necrosis factor alpha (TNF- $\alpha$ ) in peripheral blood mononuclear cells in preeclampsia and normotensive group.

Study Design: Cross-sectional comparative study.

Place and Duration of Study: The study was done in the Department of Physiology and Cell Biology, University of Health Sciences, Lahore, from November 2016 to November 2018.

Methodology: Blood samples were collected and mRNA expression of NF- $\mathrm{kB}$ and TNF- $\alpha$ was measured quantitatively by real-time polymerase chain reaction in peripheral blood mononuclear cells in 27 preeclamptic and 27 normal pregnancies. The preeclamptic group was further divided into early and late onset preeclampsia. Statistical analysis was done using SPSS (version 22).

Results: The peripheral blood mononuclear cells mRNA expression of NF- $\kappa B$ and TNF- $\alpha$ differed within the two groups with an increase in expression in the diseased group $(p<0.001)$. There was an increase of 2.79 fold in mRNA expression of TNF- $\alpha$ while the result for NF- $\alpha$ B was 2.28 fold. The difference in the expression of both NF-kB and TNF- $\alpha$ was significant within the two subgroups of preeclampsia $(p<0.001)$. TNF- $\alpha$ was found to be strongly correlated with NF-kB $(p<0.01)$.

Conclusion: mRNA expression of both NF-kB and TNF- $\alpha$ in peripheral blood mononuclear cells was found to be elevated in preeclampsia and this extra-placental source of these inflammatory mediators might have a role in the pathogenesis of widespread maternal systemic inflammation.
\end{abstract}

Key Words: Inflammation, Nuclear factor kappa B, Preeclampsia, Tumor necrosis factor alpha.

How to cite this article: Ali Z, Zafar U, Khaliq S, Lone KP. Elevated tumor necrosis factor (TNF)- $\alpha$ mRNA expression correlates with nuclear factor kappa B expression in peripheral blood mononuclear cells in preeclampsia. J Coll Physicians Surg Pak 2020; 30(2):158-162.

\section{INTRODUCTION}

Preeclampsia (PE) is a hypertensive gestational disorder characterised by a rise in blood pressure and proteinuria. It has been labelled as the disease of placental origin. Impaired remodelling of the uterine spiral arteries results in defective placentation and decreased perfusion. The resultant ischemia and hypoxia create a favourable environment for oxidative stress in placental bed with resultant release of proinflammatory cytokines and vasoactive compounds. ${ }^{1}$ Widespread systemic inflammation and endothelial dysfunction is the hallmark of preeclampsia.

Nuclear factor- $\kappa \mathrm{B}(\mathrm{NF}-\kappa \mathrm{B})$ is an oxidation-reduction sensitive transcription factor. It modulates a number of

Correspondence to: Dr. Zaima Ali, Department of Physiology and Cell Biology, University of Health Sciences, Lahore,

Pakistan

E-mail: zaima.ali@hotmail.com

Received: September 12, 2019; Revised: December 16, 2019;

Accepted: January 13, 2020 genes involved in the regulation of inflammation. In

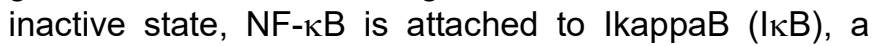
member of inhibitory protein family in the cytosol. ${ }^{2} \mathrm{~A}$ number of cytokines and oxidants can activate NF- $\mathrm{kB} .{ }^{3}$ This activation is a result of a serine specific protein kinase activity, IKB kinase (IKK) complex. TNF- $\alpha$ and Interleukin-1 (IL-1) are the most notable and potent activator of NF-KB through stimulation of IKK activity. 4 Activation of NF-kB results in displacement of its units to the nucleus leading to modification of expression of a number of genes involved in inflammation such as growth factors, cytokine receptors and tumor necrosis factor alpha (TNF- $\alpha) \cdot 3,4 \mathrm{NF}-\kappa \mathrm{B}$ is known to be activated in a number of pathologies associated with excessive oxidative stress and inflammation, e.g. atherosclerosis, AIDS, ischemia-reperfusion injuries, rheumatoid arthritis, etc. In chronic inflammatory diseases continuous activation of NF- $\kappa B$ influences severity of the disease due to increased production of adhesion molecules and chemotactic chemokines. ${ }^{5}$ Intermittent ischemia and reperfusion in the placental bed leads to release of 
reactive oxygen species (ROS), with resultant actuation of $\mathrm{NF}-\kappa \mathrm{B}$ in the placental tissue in pregnancies complicated with preeclampsia. TNF- $\alpha$, a proinflammatory cytokine is secreted by the trophoblast and this secretion is increased markedly in ischemia of the placenta. 6 TNF- $\alpha$ binds to its receptors and activates downstream

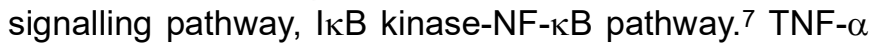
enhances the actuation of NF- $\alpha \mathrm{B}$ in trophoblast cells. 8

Considering the role of widespread systemic inflammation with activation of haemostatic system in the pathogenesis of $\mathrm{PE}$, it was hypothesised that mRNA expression of TNF- $\alpha$ is elevated and correlates with increased mRNA expression of $N F-\kappa B$ in peripheral blood mononuclear cells (PBMCs) in preeclampsia.

To test the hypothesis, the aim of the study was to evaluate mRNA expression of TNF- $\alpha$ and NF- $\kappa B$ in PBMCs in preeclampsia and normotensive pregnancies quanti-tatively by real time polymerase chain reaction (PCR).

\section{METHODOLOGY}

After approval from the Ethical Review Board, University of Health Sciences, Lahore (No: UHS/Education/126$16 / 2754$, dated $27 / 10 / 2016$ ), the study was conducted following the guidelines of the Declaration of Helsinki. Informed written consents were taken from all the participants. Blood samples were collected at a tertiary care hospital of Lahore by purposive sampling from October 2016 to March 2017. The formula for hypothesis test for two populations from WHO sample size calculator was used to calculate the sample size. ${ }^{9}$ Twentyseven pregnant women (between the ages of 18-40 years) in the third trimester (28-40 weeks) diagnosed as preeclamptic were recruited as cases; and 27 agematched normotensive pregnant women at the same gestational age were included as controls. Criteria to diagnose preeclampsia (PE) were: new onset systolic blood pressure of more than $140 \mathrm{mmHg}$ or diastolic blood pressure $>90 \mathrm{mmHg}$ after 20 week of gestation accompanied by 24 hours proteinuria $\geq 300 \mathrm{mg}(\geq 1+$ on dipstick), in at least two random urine samples collected 4-6 hours apart. All the study participants were nonsmoker. Preeclamptic group was further divided into two subgroups i.e., early onset preeclampsia (EOP) with onset of disease at gestational age of 28-32 weeks and late-onset preeclampsia (LOP) having disease at 32.1-40 weeks of gestation. There were 13 participants in EOP and 14 in the LOP subgroup. Women with history of chronic illness like chronic hypertension, diabetes mellitus, renal disease, inflammatory bowel disease, arthritis, cardiovascular illness (e.g. ischemic heart disease), or other chronic inflammatory disease were excluded. Complete medical, obstetric and family history was recorded along with demographic data. Blood pressure was recorded with sphygmomanometer.
Under aseptic measures, $5 \mathrm{ml}$ venous blood was drawn and collected in EDTA coated vacutainer. Samples were centrifuged, buffy coat was separated and stored at $-20^{\circ} \mathrm{C}$ within an hour of sample collection. For RNA extraction, Favor Prep total RNA Isolation Kit (Favorgen, Taiwan) was used following the manufacturer's instructions. Extracted RNA concentrations were measured using Nano-drop and stored in RNase/DNase free water at $-80^{\circ} \mathrm{C}$.

RevertAid First-strand cDNA Synthesis kit (Thermo Scientific, USA) was used for cDNA synthesise by reverse transcription of two micro gram of total RNA from each sample. Gene expression was measured for 27 cases and 27 controls by using synthesised cDNA. Specific gene primers (Table I) and $2 \times$ SYBR green master mix (Fermentas, USA) for real-time PCR were used on CFX 96 (Biorad, USA) following the provided protocol. All reactions were carried in $20 \mu \mathrm{l}$ of the reaction mixture with $1 \mu \mathrm{l}$ of cDNA, $8 \mu \mathrm{l}$ of 2 X SYBR green real-time PCR master-mix, $0.5 \mu$ l of each forward and reverse primers, and RNase-free water (Fermentas, USA). Real-time-PCR protocol was as: $94^{\circ} \mathrm{C}$ for $4 \mathrm{~min}$, succeeded by 30 cycles of $94^{\circ} \mathrm{C}$ for $30 \mathrm{~s}$. Annealing time was $30 \mathrm{~s}$ at $60^{\circ} \mathrm{C}$. Extension was done at $70^{\circ} \mathrm{C}$ for $42 \mathrm{~s}$ in a thermal cycle followed by melt curve analysis. All samples were assayed in duplicate and three housekeeping genes were used for data normalisation. Relative analysis of the gene expression was performed by using $2-\triangle \triangle \mathrm{ct}$ method. Confirmation of the products of the expected size was done by electrophoresis on agarose gel.

SPSS Version 22.0, Statistical Package for the Social Sciences, Armonk, New York, USA was used for analysis. Distribution of the data was analysed by Shapiro-Wilk test. The clinical parameters were expressed as median with interquartile range (IQR) and compared by Wilcoxon Rank Sum test. Mean of mRNA expression of three housekeeping genes i.e., GAPDH, $\beta$-actin, and 18srRNA was used to normalise the expression of the studied genes. The mRNA expression was compared using fold change values between two groups by Student's t-test. Gene expressions were reported as mean fold change with standard deviation (SD). Comparison within multiple groups was done by one-way ANOVA with post-hoc Tukey's test. Correlation between different gene expressions was estimated by Pearson's correlation. The p-value $<0.05$ was considered statistically significant.

\section{RESULTS}

The study population consisted of 27 women with preeclampsia and 27 healthy normotensive controls. Maternal ages and gestational age at sampling of the participants were not statistically different between preeclampsia and controls; p-value 0.49 and 0.17 , respectively (Table II). 
Gene expression between the two groups was reported as fold change. The PBMCs mRNA expressions of NF-kB and TNF- $\alpha$ were significantly different between the preeclamptic and normotensive group with an increase in the diseased group $(p<0.001)$ (Table III). There was

Table I: Sequence of primers for quantitative real time-PCR.

\begin{tabular}{|c|c|c|}
\hline Gene & Sequence & $\begin{array}{l}\text { PCR product } \\
\text { length (bp) }\end{array}$ \\
\hline TNF- $\alpha-F P$ & 5' -GGAGAAGGGTGACCGACTCA- 3' & $362 b p$ \\
\hline TNF- $\alpha-R P$ & 5' -CTGCCCAGACTCGGCAA- 3' & \\
\hline NF-kB-FP & 5'-TACTCTGGCGCAGAAATTAGGTC- 3' & 264-bp \\
\hline NF-kB-FP & 5'-CTGTCTCGGAGC TCGTCTATTTG- 3' & \\
\hline GAPDH-FP & 5' -ACG GAT TTG GTC GTA TTG GG- 3' & $214 \mathrm{bp}$ \\
\hline GAPDH-RP & 5' -CGC TCC TGG AAG ATG GTG AT -3' & \\
\hline$\beta$-actin-FP & 5' -TCC ACC TTC CAG CAG ATG TG -3' & $75 \mathrm{bp}$ \\
\hline$\beta$-actin-RP & 5' -GCA TTT GCG GTG GAC GAT -3' & \\
\hline 18s rRNA-FP & 5'-AGA AAC GGC TAC CAC ATC CAA -3' & $91 \mathrm{bp}$ \\
\hline 18s rRNA-RP & 5' -CCT GTA TTG TTA TTT GTC ACT ACC T -3' & \\
\hline
\end{tabular}

Table II: Clinical characteristics of the participants.

\begin{tabular}{l|c|c|c}
\hline & $\begin{array}{c}\text { Preeclampsia } \\
\mathrm{n}=27\end{array}$ & $\begin{array}{c}\text { Normotensive group } \\
\mathrm{n}=27\end{array}$ & $\mathrm{p}$-value \\
\hline Maternal age (years) & $26(23-30)$ & $25(22-28)$ & 0.49 \\
\hline BMI $\left(\mathrm{kg} / \mathrm{m}^{2}\right)$ & $28.9(27.6-30.3)$ & $26.1(23.8-28.6)$ & ${ }^{*}<0.01$ \\
\hline Gestational age & $32(29.2-36)$ & $30.5(28-33.5)$ & 0.17 \\
\hline Systolic BP & $150(140-160)$ & $100(100-110)$ & ${ }^{*}<0.001$ \\
\hline Diastolic BP & $100(90-100)$ & $70(60-70)$ & ${ }^{*}<0.001$ \\
\hline Parity & $2(2-3)$ & $1(1-2)$ & 0.64 \\
\hline
\end{tabular}

Values presented as Median with Inter Quartile Range (IQR)

*Significant difference between preeclampsia and normotensive group, calculated by Wilcoxon Rank Sum test.

Table III: Gene expression between different groups.

\begin{tabular}{l|l|l|l|l|l}
\hline Gene & $\begin{array}{l}\text { Normotensive } \\
\text { (a) }\end{array}$ & $\begin{array}{l}\text { Preeclampsia } \\
\text { (b) }\end{array}$ & $\begin{array}{l}\text { EOP } \\
\text { (c) }\end{array}$ & $\begin{array}{l}\text { LOP } \\
\text { (d) }\end{array}$ & -value \\
\hline TNF- $\alpha$ & 1.00 & $2.79 \pm 0.48$ & $2.49 \pm 0.40$ & $3.08 \pm 0.37$ & $\begin{array}{l}a-b<0.000^{*} \\
\text { c-d }=0.000^{* *} \\
a-c<0.000^{\star *} \\
\text { a-d }<0.000^{\star *}\end{array}$ \\
\hline NF-kB & 1.00 & $2.28 \pm 0.77$ & $1.56 \pm 0.16$ & $2.95 \pm 0.40$ & $\begin{array}{l}a-b<0.000^{*} \\
\text { c-d }<0.000^{* *} \\
a-c=0.000^{* *} \\
\text { a-d }<0.000^{* *}\end{array}$ \\
\hline
\end{tabular}

Fold Change presented as Mean \pm Standard deviation.

* $p$ value calculated by Student's $t$-test. ${ }^{* *} p$ value calculated by one-way ANOVA with post hoc Tukey's test. EOP: Early-onset preeclampsia, LOP: Late-onset preeclampsia.

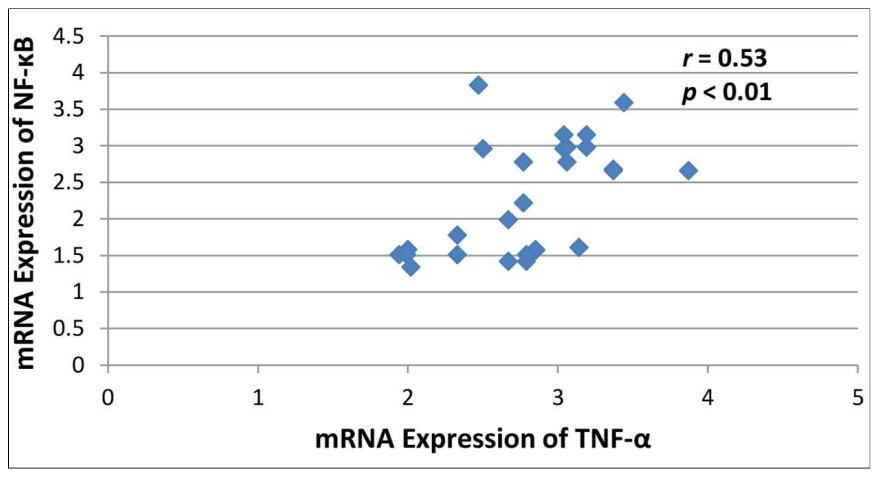

Figure 1: Correlation of TNF- $\alpha$ with NF-kB in Preeclampsia, Pearson's $r=0.53$, $p<0.01$ (Pearsons's rank correlation test showing strong positive correlation between TNF- $\alpha$ and NF-kB). an increase of 2.79 fold in mRNA expression of TNF- $\alpha$ while the result for NF-кB mRNA expression was 2.28 fold (Table III). The difference for both NF- $\kappa B$ and TNF- $\alpha$ remained significant within EOP and LOP with a more marked increase in the LOP ( $p<0.001$, Table III). TNF- $\alpha$ was found to be strongly correlated with NF-kB $(p<0.01)$ (Figure 1).

\section{DISCUSSION}

Inflammation has a central role in the generation and development of diseases of placental origin, e.g. preeclampsia, intra-uterine growth retardation (IUGR). Excessive inflammatory response in pregnancies complicated with preeclampsia leads to disturbance in the immune balance at fetal maternal interface and vascular lesions in placental bed. ${ }^{10} \mathrm{TNF}-\alpha$ is secreted by trophoblast and the secretion of this proinflammatory cytokine increases in response to ischemia in the placental bed. 6 In vitro studies have described an increase in the expression of TNF- $\alpha$ in placental tissue in response to oxidative stress produced by intermittent hypoxia and re-oxygenation. This increase in TNF- $\alpha$ in turn results in a local inflammatory reaction with increased leukocyte infiltration and interaction with syncytiotrophoblast. These activated cells have been proposed to contribute to systemic endothelial cell activation in preeclampsia. ${ }^{11}$ Furthermore, lack of the normal shift of maternal immune system towards $T$ helper 2 response in preeclampsia, results in excessive proinflammatory type 1 cytokines including TNF- $\alpha .{ }^{12}$ Excessive TNF- $\alpha$ has harmful effects by directly binding to specific receptors on the cells or indirectly by induction of other inflammatory mediators, e.g. ROS. This study has reported an increase in the mRNA expression of TNF- $\alpha$ in the PBMCs in preeclampsia in the third trimester as compared to normotensive group. This excessive expression of TNF- $\alpha$ in PBMCs provides an extra-placental source of this inflammatory mediator. In addition to trophoblast, macrophages and monocytes have been reported to produce excessive amount of TNF- $\alpha$ in the placental bed.13 Extra-placental sources like peripheral leukocytes, might contribute to the increased levels of this proinflammatory mediator. The present results highlight the contribution of systemic inflammation with involvement of the haemostatic system in the development of preeclampsia. TNF- $\alpha$ is known to enhance the release of eosinophil oxidants and activate the respiratory burst in the endothelial cells. ${ }^{14}$ Nitric oxide, a potent vasodilator is synthesised by vascular endothelium and its levels are decreased in preeclampsia. TNF- $\alpha$ inhibits the synthesis of nitric oxide. In addition, it modifies the endothelial cells from an anticoagulant to a procoagulant state by increasing the expression of tissue factor. Besides, TNF- $\alpha$ induces transcription of vascular cell adhesion molecules-1 (VCAM-1), a factor responsible for increased neutrophil 
activation and serum levels of VCAM-1 are reported to be increased in preeclampsia. ${ }^{15}$

$\mathrm{Li}$ et al. reported higher expression of NF-kB in the placental tissue in preeclampsia. ${ }^{16}$ Greater expression of NF-kB, an important transcription factor for genes involved in inflammation, has also been observed with immunohistochemical staining in systemic vessels in preeclampsia. The expression was increased both in endothelium and vascular smooth muscles of the vessels and was coincident with increased expression of an inflammatory mediator, cyclooxygenase-2 (COX-2). The leukocytes in the vessel lumen as well as those adhered to intima also showed increased expression of both NF-kB and COX-2.17 It was hypothesised that the expression of NF-kB is increased in the PBMCs in preeclampsia; and to the best of our knowledge, this finding of increased mRNA expression of NF-kB in the PBMCs by real time PCR in preeclampsia is novel to this study. The expression of both TNF- $\alpha$ and NF-kB was significantly different within the two subgroups of preeclampsia with a more marked increase in LOP. In contrast, previously, Borges and colleagues (2015) reported higher levels of TNF- $\alpha$ in the blood 18 while Weel et al. reported an increase in TNF- $\alpha$ in the placental tissue in EOP. ${ }^{19}$ Both these studies reported significant difference in TNF- $\alpha$ in pregnancies complicated with preeclampsia as compared to controls ( $p$ value $<0.05$ ). Early-onset PE patients present with more severe disease and higher levels of blood pressure and proteinuria. Although the percentage of patients with higher systolic and diastolic blood pressures was high in the EOP, the difference in the severity of the disease was not statistically significant in the current study ( $p$ value >0.05). The difference in the results might be attributed to small sample size. Adcock et al. have reported stimulation and translocation of NF-kB by 200 percent on exposure of PBMCs to TNF- $\alpha .{ }^{20}$ We tested the hypothesis that the elevated expression of TNF- $\alpha$ in PBMCs in preeclampsia correlates with increased NF-kB expression. This study has reported a strong positive correlation between mRNA expression of TNF- $\alpha$ and NF-kB in PBMCs in preeclampsia. This increase in NF-kB expression in PBMCs might contribute as an extra placental source to enhance widespread maternal endothelial dysfunction. In support of our results are the increased levels of proinflammatory TNF- $\alpha$, IL- 6 and NF-kB in monocytes exposed to plasma from preeclamptic pregnancies reported by Rahardjo and colleagues in $2014 .{ }^{21} \mathrm{NF}-\mathrm{kB}$ regulates the expression of various genes concerned with inflammation and immune responses, e.g. interleukin-8, E-selectin and TNF- $\alpha$. Coactivation of the expression of these genes leads to stimulation of leukocytes, enhancing inflammation. In turn, the products of these genes activate NF- $\kappa B$, forming a positive regulatory loop and amplifying inflammatory response. 5 In 2018, Zheng and colleagues stratified the patients by severity of disease as mild and severe preeclampsia and studied the mRNA expression of NF-kB in the placental tissue. They reported higher $\mathrm{NF}-\mathrm{kB}$ expression in the placental tissue in severe PE as compared to mild PE.22 In view of these results, where expression intensity of $\mathrm{NF}-\mathrm{kB}$ reflects the severity of the disease, role of NF-kB can be implied in the pathogenesis of preeclampsia. Our findings of increased expression of NF-kB in PBMCs support the theory of generalised immune activation in preeclampsia. These results augment the previously reported finding of activation of PBMCs through NF-kB pathway. ${ }^{23}$ Although a lot of work has been done on placental tissue, the role of PBMCs in altered immune system and inflammation in preeclampsia needs further investigation. If future studies support the present results, detection of these markers at an early stage might help in diagnosis of the disease. Furthermore, targeting these inflammatory markers may be a promising interventional approach for preeclampsia. It is easy to collect blood samples as compared to placental tissue. One-time sample collection in the third trimester is the limitation of this study. Multiple serial samples in all the trimesters would highlight the role of these inflammatory markers in the development of preeclampsia.

\section{CONCLUSION}

In conclusion, mRNA expression of both NF-kB and TNF-a in PBMCs is elevated in preeclampsia and this extra placental source of these inflammatory mediators might have a role in the pathogenesis of widespread maternal systemic inflammation.

\section{ETHICAL APPROVAL:}

The study was approved by the Institutional Review Board of University of Health Sciences, Lahore.

\section{PATIENTS' CONSENT:}

Informed written consents were obtained from all individual participants included in the study.

\section{CONFLICT OF INTEREST:}

Authors declared no conflict of interest.

\section{AUTHORS' CONTRIBUTION:}

ZA: Literature survey, concept, expression analysis and manuscript write-up.

UZ: Analysis and interpretation of the data and manuscript write-up.

SK: Literature survey, expression analysis and revision of the manuscript.

KPL: Conceived the idea and proofread the manuscript.

\section{REFERENCES}

1. Jauniaux E, Poston L, Burton GJ. Placental-related diseases of pregnancy: Involvement of oxidative stress and implications in human evolution. Hum Reprod Update 2006; 12:747-55. 


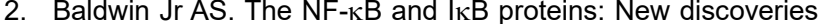
and insights. Annu Rev Immunol 1996; 14:649-81.

3. Winyard PG, Blake DR. Antioxidants, redox-regulated transcription factors, and inflammation. Adv Pharmacol 38: Adv Pharmacol 1997; 38:403-21.

4. Karin $M$. The beginning of the end: IKB kinase (IKK) and NF-kB activation. J Biol Chem 1999; 274:27339-42.

5. Barnes PJ, Karin M. Nuclear factor- $\mathrm{B}$ : A pivotal transcription factor in chronic inflammatory diseases. New Engl J Med 1997; 336:1066-71.

6. Zhou P, Luo X, Qi HB, Zong WJ, Zhang H, Liu DD, et al. The expression of pentraxin 3 and tumor necrosis factor-alpha is increased in preeclamptic placental tissue and maternal serum. Inflamm Res 2012; 61:1005-12.

7. Hsu H, Shu HB, Pan MG, Goeddel DV. TRADD-TRAF2 and TRADD-FADD interactions define two distinct TNF receptor 1 signal transduction pathways. Cell 1996; 84:299-308.

8. Vaughan JE, Walsh SW. Activation of NF-kB in placentas of women with preeclampsia. Hypertens Pregnancy 2012; 31: 243-51.

9. Perucci LO, Gomes KB, Freitas LG, Godoi LC, Alpoim PN, Pinheiro $M B$, et al. Soluble endoglin, transforming growth factor-beta 1 and soluble tumor necrosis factor alpha receptors in different clinical manifestations of preeclampsia. PloS One 2014; 9:e97632.

10. Qian Z, Zeng Y, Zhu B, Yuhua J, Fang H. Detection of systematic oxidative stress in preeclampsia. Basic Clin Med 2010; 30:343-7.

11. Hung TH, Charnock-Jones DS, Skepper JN, Burton GJ. Secretion of tumor necrosis factor- $\alpha$ from human placental tissues induced by hypoxia-reoxygenation causes endothelial cell activation in vitro: A potential mediator of the inflammatory response in preeclampsia. Am J Pathol 2004; 164:1049-61.

12. Saito S, Shiozaki A, Nakashima A, Sakai M, Sasaki Y. The role of the immune system in preeclampsia. Mol Aspects Med 2007; 28:192-209.

13. Boyle JJ, Weissberg PL, Bennett MR. Tumor necrosis factor- $\alpha$ promotes macrophage-induced vascular smooth muscle cell apoptosis by direct and autocrine mechanisms. Arterioscler Thromb Vasc Biol 2003; 23:1553-8.

14. Slungaard A, Vercellotti GM, Walker G, Nelson R, Jacob HS. Tumor necrosis factor alpha/cachectin stimulates eosinophil oxidant production and toxicity towards human endothelium. $J$ Exp Med 1990; 171:2025-41.

15. Kim SY, Ryu HM, Yang JH, Kim MY, Ahn HK, Lim HJ, et al. Maternal serum levels of VCAM-1, ICAM-1 and E-selectin in preeclampsia. J Korean Med Sci 2004; 19:688-92.

16. Li X. Study on the correlation between onset, degree of severity of preeclampsia and NF-kB, TNF- $\alpha$, PLGF [J]. Matern Child Health J 2014; 12:1849-51.

17. Shah TJ, Walsh SW. Activation of NF-kB and expression of COX-2 in association with neutrophil infiltration in systemic vascular tissue of women with preeclampsia. Am J Obstet Gynecol 2007; 196:48.e1-.e8.

18. Borges VT, Peraçoli JC, Romão M, Zanati S, Poiati JR, Weel IC, et al. [303-POS]: Differentiation between early and late preeclampsia by inflammatory cytokines and the association between IL-1 $\beta$ and left cardiac hypertrophy. Pregnancy Hypertens 2015; 5:150.

19. Weel IC, Baergen RN, Romão-Veiga M, Borges VT, Ribeiro VR, Witkin SS, et al. Association between placental lesions, cytokines and angiogenic factors in pregnant women with preeclampsia. PloS One 2016; 11:e0157584.

20. Adcock I, Brown C, Gelder C, Shirasaki H, Peters M, Barnes PJ. Effects of glucocorticoids on transcription factor activation in human peripheral blood mononuclear cells. Am J Physiol 1995; 268:C331-C8.

21. Rahardjo B, Widjajanto E, Sujuti H, Keman K. Different levels of IL-1 $\alpha$, IL-6, TNF- $\alpha$, NF- $\kappa B$ and PPAR- $\gamma$ in monocyte cultures exposed by plasma preeclampsia and normotensive pregnancy. Pregnancy Hypertens 2014; 4:187-93.

22. Zheng L, Shi L, Zhou Z, Chen X, Wang L, Lu Z, et al. Placental expression of AChE, $\alpha 7 n A C h R$ and NF-kB in patients with preeclampsia. Ginekol Pol 2018; 89:249-55.

23. Luppi P, Tse H, Lain KY, Markovic N, Piganelli JD, DeLoia JA. Preeclampsia activates circulating immune cells with engagement of the NF-kB pathway. Am J Reprod Immunol 2006; 56: $135-44$. 